\title{
Posicionamento e lugar dos agentes na crítica cultural: um estudo sobre a relação entre valores-notícia e hie
}

Mauro Ventura

\section{Resumo:}

Este artigo estuda a crítica cultural praticada na atualidade a partir das relações existentes entre valoresnotícia e hierarquia das legitimidades. Para isso, toma por base as reflexões de Pierre Bourdieu acerca das posições ocupadas pelos agentes (jornalistas, críticos e acadêmicos) no interior dos campos de produção, reprodução, consagração e difusão de bens simbólicos. De acordo com o teórico, há uma relação direta entre a tomada de posição de um agente e o lugar por ele ocupado no campo. A hipótese aqui desenvolvida, e aplicada ao estudo de três posicionamentos críticos veiculados recentemente na mídia, é a de que, quanto mais à margem de determinado campo situa-se um agente, maior é a possibilidade de que este agente se posicione de maneira não legitimada, e, por isso mesmo, menos interdependente em relação às instâncias de difusão e consagração.

\section{Palavras Chave:}

Crítica cultural, valores-notícia, hierarquia das legitimidades.

\section{Abstract:}

This paper studies the cultural criticism practiced today from the relationship between "news values" and hierarchy of legitimacy. To do so, builds on the ideas of Pierre Bourdieu on the positions held by agents (journalists, critics and academics) within the fields of production, reproduction, consecration and distribution of symbolic goods. According to Bourdieu, there is a direct relationship between the position of an agent and the place hold in the field. The hypothesis developed here and applied to study three critical positions conveyed in the media recently, is that the more an agent is located at the margin of a field, the greater the possibility that this agent will be positioned in a non-legitimate way and, therefore, less interdependent towards multipliers and consecration.

\section{Keywords:}

Cultural criticism, news value, hierarchy of legitimacy.

\section{Introdução}

Ao discorrer sobre o processo de autonomização do sistema de produção, circulação e consumo dos bens simbólicos, Pierre Bourdieu (2007: 99-100) enumera três grandes transformações operadas no decorrer dos séculos 18 e 19: a formação gradual de um público consumidor, a constituição de um segmento de empresários de bens simbólicos marcado pela profissionalização e, por fim, a diversificação de instâncias de consagração (como as academias e salões) e de instâncias de difusão (como as casas editoriais, os empresários de teatro e, em especial, a imprensa).

Esse conjunto de elementos, somado à formação de uma "categoria socialmente distinta de artistas ou de intelectuais profissionais" (BOURDIEU, 2007: 101), atua paulatinamente rumo à formação de um campo artístico autônomo e contribui para a elaboração de critérios para a definição da função desses agentes e 
de suas produções no interior do campo. Em outras palavras, o processo descrito por Bourdieu não é outra coisa senão a constituição da indústria cultural e, dentro desse sistema, interessa ao escopo desse artigo examinar o processo de formação do jornalismo e da crítica enquanto produção de bens simbólicos culturais.

Fator crucial nesse processo é a suposta autonomia que acompanha a própria constituição do campo cultural enquanto tal. Ora, se é verdade, como afirma Bourdieu, que a vida intelectual e artística libertouse progressivamente do domínio da aristocracia e da Igreja, também é certo que esta liberdade revelou-se parcial, já que suas demandas éticas e estéticas passaram a estar vinculadas às leis do mercado.

A ruptura dos vínculos de dependência em relação a um patrão ou a um mecenas e, de modo geral, em relação às encomendas diretas (...) propicia ao escritor e ao artista uma liberdade que logo se lhes revela formal, sendo apenas a condição de sua submissão às leis do mercado de bens simbólicos, vale dizer, a uma demanda que, feita sempre com atraso em relação à oferta, surge através dos índices de venda e das pressões, explícitas ou difusas, dos detentores dos instrumentos de difusão, editores, diretores de teatro, marchands de quadros (BOURDIEU, 2007: 104).

Da passagem acima interessa-nos destacar dois aspectos: a condição de submissão das instâncias de difusão às contingências de mercado e a posição de inferioridade das demandas em relação à oferta de bens simbólicos. Consideramos esses dois aspectos cruciais para estabelecer uma posição crítica em relação aos critérios de noticiabilidade praticados pelo jornalismo cultural na atualidade. Como assinala Traquina, os também chamados valores-notícia são fatores centrais da cultura jornalística, pois são eles que determinam "se um acontecimento ou assunto é suscetível de se tornar notícia, isto é, de ser julgado como merecedor de ser transformado em matéria noticiável e, por isso, possuindo valor-notícia". (TRAQUINA, 2005: 63).

Nesse sentido, cabe investigar como operam os valores-notícia e que sentido adquirem na prática do jornalismo cultural. Concebido enquanto instância especializada da práxis comunicacional, o jornalismo cultural necessita ser pensado a partir dos critérios de noticiabilidade que instaura na dinâmica própria de seu campo. Interessa, portanto, investigar os modos de organização, circulação e recepção dos bens simbólicos a partir dos conceitos de campo da difusão e hierarquia das legitimidades (BOURDIEU, 2007), e tendo em vista igualmente o conceito de intermediação cultural, termo utilizado já há longa data, mas recentemente sistematizado por Featherstone (1995).

De início, cabe destacar que o jornalismo cultural está situado no interior do campo da difusão, e que este, por sua vez, mantém relação direta com as instâncias de reprodução e de consagração. Vejamos, então, como funciona a relação entre esses campos.

Tomando-se por base as reflexões de Bourdieu, interessa ao escopo deste estudo investigar o funcionamento das relações constitutivas do campo da difusão, pois é no interior deste que atuam os agentes de difusão, como os jornalistas, os críticos e os editores. Com efeito, observa-se uma relação de oposição e de complementariedade - ou interdependência, se preferirmos - entre o campo da difusão e as instâncias de reprodução e de consagração. Ao mesmo tempo, uma idêntica relação de interdependência, embora com funções distintas, marca a dinâmica entre os campos da produção (erudita e indústria cultural, para falarmos como Bourdieu) e da difusão.

Todo o problema ligado aos critérios de noticiabilidade deriva desse conjunto de relações ou desta economia das trocas simbólicas. Como entender, por exemplo, as relações entre os produtores e as instâncias de consagração sem examinar o processo dinâmico e muitas vezes arbitrário que marca a hierarquia das legitimidades? (BOURDIEU, 2007:.118). Tal estrutura de "relações de força simbólica 
exprime-se, em um dado momento do tempo, por intermédio de uma determinada hierarquia das áreas, das obras e das competências legítimas" (BOURDIEU, 2007: 118).

Ora, tal hierarquia daquilo que é ou não legítimo influencia a relação que os agentes dos campos de produção, reprodução ou difusão estabelecem entre si e com as diferentes instâncias de legitimação. De acordo com Bourdieu, todas as formas de reconhecimento "não passam de formas diversas de cooptação cujo valor depende da posição dos cooptantes na hierarquia da consagração" (2007: 119).

\section{Valores-notícia e crítica jornalística}

Essas relações objetivas entre agentes e entre estes e as instâncias de consagração estão na base daquilo que pode ou não obter legitimidade para ser transformado em notícia ou de ser objeto de crítica (cultural, literária, cinematográfica etc) na mídia. É nesse sentido que procuramos acentuar a relação entre o exercício da crítica jornalística e os chamados critérios de noticiabilidade, na medida em que obedecem a uma lógica que os precede (2). Assim, interessa saber a que mecanismos estão submetidos tais valores e quais são os fatores responsáveis por transformá-los em critérios da atividade jornalística.

Nesse sentido, o jornalismo cultural, mas não apenas este, cumpre uma função de legitimação ao transformar estes ou aqueles fatos culturais em notícia, delimitando aquilo que merece ser transmitido, difundido, criticado e, por isso mesmo, conservado, daqueles fatos que não o merecem. $\mathrm{O}$ mesmo pode ser dito das fontes. A partir de que momento, ou em função de que contingências, determinado agente é transformado em fonte de informação? Como se dá esse processo de legitimação?

Também no plano narrativo poderíamos dizer que há uma maneira legítima e uma maneira ilegítima de contar as notícias legítimas. Com efeito, talvez não seja um excesso afirmar que a grande mídia acaba por cumprir uma função homóloga à da igreja, já que está investida do poder de defender uma ortodoxia jornalística, cristalizada nos valores-notícia acima referidos e que, no dizer de Stuart Hall, fornecem os parâmetros para as atividades produtivas do jornalismo. São esses elementos que

permitem aos jornalistas, diretores e agentes noticiosos decidir rotineiramente e regularmente sobre quais as "estórias" que são "noticiáveis" e quais não são, quais as "estórias" que merecem destaque e quais as que são relativamente insignificantes, quais as que são para publicar e quais as que são para eliminar. (Apud TRAQUINA, 2005: 176)

No âmbito específico da chamada crítica cultural - que é aquela produzida, em grande parte, ou por especialistas, ou por diletantes, para ser publicada na mídia, além do conteúdo produzido por jornalistas no interior das redações - os argumentos de Bourdieu encontram fértil aplicação. Em especial, no que se refere às posições ocupadas pelos agentes (jornalistas, críticos e acadêmicos) no interior dos campos de produção, reprodução, consagração e difusão de bens simbólicos. De acordo com o teórico, há uma relação direta entre a tomada de posição de um agente e a posição por ele ocupada no campo.

Mais ainda: observa-se entre os agentes de difusão uma tendência a conservar e reforçar as hierarquias oriundas do campo da produção. Escreve Bourdieu:

Sabendo-se a posição que os especialistas da difusão ocupam na estrutura do sistema e que lhes obriga, como vimos, a procurar em favor de sua atividade contestada as cauções mais consagradas pelo recurso ao poder que lhes assegura o controle dos instrumentos de difusão, envolvendo em seu próprio terreno os produtores de bens legítimos, sua ação vai se exercer paradoxalmente no sentido da conservação e do reforço das hierarquias mais conhecidas e reconhecidas (BOURDIEU, 2007: 157). 
O que é importante destacar é a relação de interdependência existente entre os agentes de difusão e os produtores. Veja-se, por exemplo, o uso intensivo que o jornalismo cultural faz das autoridades acadêmicas, a tal ponto que leva Bourdieu a falar em uma troca de notoriedade por legitimação cultural.

Embora não contem com os meios para conceder uma consagração cujos princípios estariam em suas mãos, o jornalista e o vulgarizador não fazem outra coisa senão mercadejar a notoriedade que estão em condições de oferecer em troca da caução que lhes podem dar com exclusividade os membros das instâncias mais consagradas de consagração, caução que lhes é indispensável na produção plena do efeito de allodoxia, princípio de seu poder aparentemente cultural sobre o público. (BOURDIEU, 2007: 156).

As palavras de Bourdieu ecoam a conhecida, e profundamente pessimista, avaliação de Adorno sobre as relações do crítico cultural com o mercado.

A crítica cultural lembra geralmente o gesto do comerciante regateador, como no caso do especialista que contesta a autenticidade de um quadro ou o classifica entre as obras menores de um mestre. Despreza-se o objeto para lucrar mais (ADORNO, 1998: 11).

Ao equiparar a tarefa da crítica à atitude do comerciante, Adorno na prática liquida as possibilidades de atuação isenta do crítico, já que este inevitavelmente necessita se envolver na esfera da mercantilização da cultura. Acreditamos, no entanto, que a formulação de Bourdieu pode significar um avanço para o beco sem saída da posição adorniana, na medida em que desloca a questão para o âmbito da relação entre tomadas de posição e posicionamento do crítico no campo da cultura.

Muito embora possuam o poder de difundir e, com isso, contribuir para a consagração de um determinado produtor - e nesse sentido as instâncias de difusão atuam também como instâncias de consagração - os intermediários culturais (sejam eles repórteres, editores e críticos) parecem estar imunes a este poder de quase consagrar, quando se trata de si mesmo. É evidente que, tanto a tendência à espetacularização da notícia, quanto o culto às celebridades podem transformar o jornalista numa espécie de oráculo, ganhando legitimação a ponto de deixar de ser apenas um intermediário para assumir uma posição de pseusoespecialista, fazendo e desfazendo reputações.

Dito de outro modo, acreditamos que recorrer a uma abordagem sócio-cultural da produção intelectual e artística para fundamentar este estudo sobre algumas práticas do jornalismo cultural na atualidade pode iluminar as marcas de posição que determinados agentes de produção e de difusão apresentam e, com isso, estabelecer uma relação com o lugar que ocupam em seus respectivos campos.

Seja como for, não se pode refletir sobre os valores-notícia no jornalismo cultural sem levar em conta a posição que os agentes (produtores e intermediários) ocupam na hierarquia da legitimidade cultural, construída por meio de signos de reconhecimento ou exclusão, do legítimo e do não-legítimo. Assim, os critérios de noticiabilidade acima elencados devem ser analisados à luz desta lógica, que preside a própria lógica do mercado de bens simbólicos.

\section{Posicionamento crítico e posição dos agentes no campo cultural}

A fim de buscar uma aplicação do problema da relação entre a posição dos agentes e suas respectivas tomadas de posição, vamos examinar três exemplos de posicionamentos críticos veiculados na mídia recentemente. Foram escolhidos três artigos críticos, dois publicados na grande mídia e um veiculado numa revista de cultura. Os exemplos escolhidos são: um artigo que contesta a consagração dada à obra 
de Marcel Duchamp; um texto que formula uma crítica veemente à $28^{a}$ Bienal de Arte de São Paulo; e uma análise dos processos de validação e de legitimação de determinadas obras literárias instituído pelo Modernismo brasileiro, no contexto de sua consagração como campo de estudos legítimo (3).

Os três posicionamentos críticos têm em comum o fato de seus autores - Affonso Romano de Sant'Anna, Aracy Amaral e Luís Augusto Fischer, respectivamente - estarem situados fora ou, no mínimo, à margem dos campos artístico e literário aos quais pertencem os objetos e eventos que criticam. O objetivo desta análise será mostrar a existência de uma relação de interdependência entre julgamento crítico e a posição ocupada pelo crítico no campo.

A crítica de Affonso Romano de Sant'Anna a Marcel Duchamp tem como gancho factual a retrospectiva do artista no Museu de Arte Moderna de São Paulo. O crítico inicia sua análise com uma argumentação que questiona precisamente as leituras legitimadas da obra do artista.

Duchamp tem sido vítima de dois tipos de leitura: a primeira é uma leitura precária, superficial, repetitiva do que vem sendo dito há 100 anos. Pura celebração, escrita de endosso, subserviente, intimidada diante da celebridade e da história. A rigor, é uma leitura antiduchampiana. É o que se faz nos cursos de arte e nos manuais. O segundo tipo de leitura que vitimou Duchamp é a hiperinterpretação. Aí se situam grandes ensaístas, tanto Octávio Paz e sua alucinada interpretação do grande vidro ou Jean Clair que compara Marcel Duchamp a nada mais nada menos que Leonardo da Vinci. (SANT'ANNA, 2008).

Além de uma crítica às interpretações legitimadas de Duchamp, Sant'Anna lembra que tais leituras são adotadas pelas instâncias de reprodução, em especial pelo sistema de ensino (cursos de arte e manuais). Quando faz objeções a Octavio Paz, Sant'Anna está questionando a recepção crítica legitimada do artista, já que Paz é um ensaísta consagrado pela academia, ainda que tenha feito carreira à margem dela.

É este o ponto que gostaria de destacar: Sant'Anna é um produtor situado fora do campo da crítica de arte, e, muito embora seja consagrado enquanto poeta, ainda não é detentor, enquanto crítico, desta legitimação. Penso que seus posicionamentos sobre a arte conceitual (tema legitimado e hegemônico tanto na academia quanto na mídia) devem dificultar ainda mais sua legitimação enquanto crítico de arte. Estamos diante de um agente de reprodução não legitimado, que se posiciona sobre um tema legítimo a partir de uma abordagem não-legítima.

Isto ocorre, segundo o ponto de vista que adotamos neste estudo, em função da existência de abordagens legítimas e não-legítimas para temas e/ou autores legítimos ou não-legítimos. Nossa hipótese é a de que, quanto mais à margem de determinado campo situa-se um agente, maior é a possibilidade de que este agente se posicione de maneira não legitimada, já que o grau de interdependência do agente em relação às instâncias de difusão e consagração é menor.

A crítica de Sant'anna à consagração da obra de Duchamp é reveladora também de um conflito que envolve duas maneiras distintas de aquisição dos bens culturais: o conhecimento herdado e o conhecimento adquirido, configurados respectivamente nas instâncias da família e da escola. Quando o que está em jogo é a relação com a obra de arte, verifica-se, como no dizer de Bourdieu,

uma oposição entre aqueles que estão identificados com a definição escolar da cultura e com o modo escolar de aquisição, por um lado, e, por outro, aqueles que se tornam os defensores de uma cultura e de uma relação com a cultura mais "livres", menos estritamente subordinadas às aprendizagens e aos controles escolares. (BOURDIEU, 2008: 88). 
Transferindo o raciocínio para o campo estrito do jornalismo e da crítica culturais, poderíamos falar de abordagens e critérios hegemônicos (legítimos) e não-hegemônicos (não-legítimos). Na esteira de um pensamento crítico sobre a cobertura de cultura na mídia, esta dimensão somente seria atingida se buscássemos estabelecer novos parâmetros e critérios de noticiabilidade para esta área.

Sant'Anna vai além em sua crítica, chegando a propor uma revisão conceitual da modernocontemporaneidade: "o dessacralizador foi sacralizado e os que o seguem são paradoxalmente antiduchampianos", escreve (SANT'ANNA, 2008). Preocupado em desconstruir o mito Duchamp, Sant'Anna parece ter consciência do quanto sua crítica permanece à margem das abordagens estabelecidas. Como último argumento, ele cita a ironia de Duchamp ao ingressar, no final da vida, na Academia Nacional de Letras e Artes dos Estados Unidos. "Assim o apóstata voltou ao seio da Igreja", escreve.

Ao entrar numa instância de consagração, como a Academia, é o próprio potencial iconoclasta de Duchamp que se dilui na distinção. Com isso, o artista ganha seu passaporte para a legitimação. Desconstruir essa dominância cultural, fazer frente a esta violência simbólica é o objetivo da crítica de Sant'Anna, crítico não legitimado e, portanto, segundo nossa hipótese, em condições mais favoráveis de formular tal posicionamento.

O problema não é simples, e segue sua formulação, agora com a análise da crítica de Aracy Amaral à $28^{\mathrm{a}}$ Bienal de Arte de São Paulo. Este talvez seja o exemplo mais incisivo dos três escolhidos para análise. Sua autora, uma prestigiada historiadora e crítica de arte, formula uma crítica ao campo das artes em três dimensões: são objeto de sua atenção a instituição Bienal, os artistas legitimados pela instituição e a produção dos especialistas vinculados ao campo.

$\mathrm{O}$ argumento de Amaral norteia-se pela pergunta se esta edição da Bienal refletiria ou não o atual estágio da arte. Eis a resposta, direta e incisiva. "A indigência presente na Bienal não reflete a arte contemporânea. Ela é antes espelho da debilidade de uma instituição" (AMARAL, 2008). A crítica à instituição estende-se à presidência, à curadoria e ao conselho da Bienal.

Se entre nós o problema foi falta de verba que caberia à presidência da Bienal providenciar, essa presidência está no lugar equivocado, pois essa é a sua competência. Se a escolha do curador foi tardia, a responsabilidade é da instituição e da curadoria que aceitou (AMARAL, 2008).

A análise se desdobra também num ataque virulento ao "Conselhão", classificado por ela de círculo fechado formado por aqueles que "decidem o que entra e o que não entra" (AMARAL, 2008).

O segundo aspecto do texto de Amaral concentra-se na crítica aos artistas selecionados, todos representantes da arte conceitual e legitimados apenas em função de pertencerem a esta corrente artística, que, aliás, ocupa o topo da hierarquia das legitimidades. "Esta Bienal parece antes preconceituosa - em sua preocupação em não mostrar artistas de outras tendências, mas apenas aqueles rigorosamente conceituais" (AMARAL, 2008).

É por este motivo que Amaral sustenta que a Bienal correu o risco de passar ao visitante a "falsa impressão de que nada mais ocorre na área" (AMARAL, 2008). O artigo em questão é relevante no contexto de uma economia das trocas simbólicas, na exata medida em que elege como alvo de crítica todos os agentes do campo, incluindo aí os próprios críticos, a mídia e o sistema de galerias e museus.

$\mathrm{Na}$ verdade, há algo de cinismo murmurado, reconhecido e vivenciado no meio artístico 
contemporâneo. O conceitual é bem imaterial, mas aqueles que sobrevivem vendem, ou viajam a convite para expor suas criações. A própria crítica, as curadorias, a mídia, o sistema de galerias e museus, todos enfim contribuímos amplamente para esse fim, apesar do que se publica em vários países sobre esse fenômeno. Isso se deve ao fato de se escrever, em geral em literatura pouco acesssível ou pedante, sobre obras sem nenhum ou parco valor, para um público reduzido que acredita erroneamente que quanto mais hermético mais elevado (AMARAL, 2008).

A passagem acima, além de sintetizar os argumentos já elencados da crítica de Amaral à $28^{\mathrm{a}}$ Bienal de Arte, aprofunda a questão ao tocar no problema da linguagem, do hermetismo que caracteriza as teorizações a respeito da arte conceitual.

Há determinadas categorias de críticos que, diante da necessidade de se legitimar, lançam mão de signos exteriores em sua tarefa de conceder a consagração cultural. Decorre disso a "necessidade de adotar o tom douto e sentencioso, o culto da erudição pela erudição da crítica universitária, ou de procurar uma caução teórica, política ou estética nas obscuridades de uma linguagem tomada de empréstimo" (BOURDIEU, 2007: 155). Tal fenômeno ocorreu com a recepção da arte conceitual: ao esforço dos artistas em defender suas criações veio juntar-se o trabalho de interpretação do campo acadêmico, que não apenas conferiu consagração cultural, mas impôs um cânone aos estudiosos da arte contemporânea, com a delimitação de temas, autores e abordagens legítimas.

Problema idêntico pode ser verificado no posicionamento do crítico Luís Augusto Fischer em relação à "centralidade excessiva que o modernismo de feição paulistana ocupa na atual descrição da literatura e da cultura brasileiras" (FISCHER, 2007: 128).

$\mathrm{Na}$ hierarquia das legitimidades, o modernismo é um tema hegemônico, ao passo que a expressão regionalismo padece de um rebaixamento nessa mesma hierarquização. Explica Fischer:

A validação das obras, o carimbo de legitimidade que elas podem receber, pelo menos desde o Modernismo brasileiro, está ligado à idéia de que (a) a cidade é a totalidade, a cidade grande em particular; (b) a ponta do processo de modernização é o que importa, em qualquer nível (social, econômico, político), a ponta e não as bordas ou a retaguarda, porque na ponta é que os conflitos se expressariam de modo direto, se tornam visíveis a pleno; (c) arte é igual a novidade, a vanguarda, arte verdadeira implica conquista de novo território temático, de novo procedimento formal, e toda arte que apresentar qualquer aspecto de permanência rebaixa imediatamente o valor dessa arte (FISCHER, 2007: 134).

Estamos diante daquilo que Bourdieu identifica como uma luta no interior de um determinado campo. Os agentes tendem a "transformar em escolhas epistemológicas os interesses associados à posse de um tipo determinado de capital científico e a uma posição determinada no campo científico" (BOURDIEU, 2007: 171).

Com efeito, o objeto da crítica de Fischer está em caracterizar a posição que o modernismo ocupa na hierarquia propriamente cultural da legitimidade e a conseqüente deslegitimação do conceito de regionalismo.

A soma desses pressupostos resulta na entronização de certo tipo de literatura não como um estilo, uma variedade, mas como a melhor literatura e, nos casos mais extremos, a única literatura (a única arte, nos casos delirantes) válida (FISCHER, 2007: 134).

O argumento de Fischer concentra-se na identificação daqueles fatores que interferem nas leis de 
funcionamento de um determinado campo. Trata-se das escolhas metodológicas e epistemológicas operadas pelos agentes -- no caso, os produtores do campo acadêmico, responsáveis pelo processo de consagração, e os agentes das instâncias de difusão, como a mídia - com a finalidade de legitimar ou não este ou aquele conceito, fazendo com que se tornem dominantes os juízos da crítica legitimadora no que se refere ao depreciado conceito de modernismo e o seu correlato regionalismo. Escreve o crítico:

Antes de mais nada, preste um pouco de atenção à faca com que está sendo fatiada a história da literatura brasileira, e veja que ela existe, para começo de conversa; depois tente avaliar a natureza dessa faca, o ângulo de corte que ela opera; depois tente retornar para a literatura brasileira ela mesma, quero dizer, para os livros, os importantes e os não importantes, e tente ver se eles não seriam mais bem descritos segundo outras fatias, mediante outros recortes, com o uso de outra faca (FISCHER, 2007: 135)

Não obstante, também a posição ocupada por Fischer no campo da crítica literária brasileira é relevante para a discussão: situado geográfica e academicamente numa posição periférica, Fischer busca levantar suspeitas sobre um tema legitimado tanto pelo campo da produção quanto pelas instâncias de consagração.

Ora, como toda tomada de posição é determinada em boa medida pela posição ocupada por aquele que a produz, lançamos a hipótese de que a tomada de posição assumida por Fischer, deslegitimadora em relação ao Modernismo paulista (assim como a supervalorização de Mário de Andrade pela recepção crítica), está determinada pela posição não hegemônica ocupada por seu autor na hierarquia propriamente cultural da legitimidade.

A pergunta que fica é a seguinte: estivesse Fischer posicionado no centro do campo acadêmico, estaria ele em condições (leia-se livre de condicionamentos) de formular tal posicionamento crítico?

A pergunta não soará descabida se levarmos em conta, como temos ressaltado ao longo deste estudo, que as posturas críticas assumidas por determinados agentes de produção e de difusão estão diretamente ligadas ao lugar que ocupam em seus respectivos campos. Toda reflexão sobre os critérios de noticiabilidade e de criticabilidade no jornalismo cultural precisa estar ancorada sobre um trabalho de esclarecimento sobre as posições ocupadas pelos agentes (produtores e intermediários) na hierarquia da legitimidade cultural, construída por meio de sinais de distinção ou de exclusão, de legitimação ou de não-legitimação.

Nossa hipótese é a de que, quanto mais à margem de determinado campo estiver situado um agente, maior é a possibilidade de que este agente se posicione de maneira não legitimada - e com isso escolha temas e abordagens igualmente não legitimados. E como o grau de interdependência do agente em relação às instâncias de difusão e consagração tende a ser menor nesses casos, acreditamos que, por conta da posição ocupada pelo agente, o potencial de crítica ao campo tende a ser maior e mais favoráveis são as condições para a prática deste posicionamento.

\section{Bibliografia:}

ADORNO, Th. Prismas. Crítica cultural e sociedade. Trad. Augustin Wernet e Jorge Almeida. São Paulo: Ática, 1998

AMARAL, A. "Esta Bienal reflete a arte contemporânea?" O Estado de S. Paulo, 21/out/2008, Caderno 2, p. D 8-9. 
BOURDIEU, P. "O mercado de bens simbólicos". In: A economia das trocas simbólicas. Introd., org. e sel. Sergio Miceli. 6 ${ }^{\text {a }}$ edição. São Paulo: Perspectiva, 2007, p.99-181.

BOURDIEU, P. A distinção. Crítica social do julgamento. Trad. Daniela Kern; Guilherme Teixeira. São Paulo: Edusp; Porto Alegre: Zouk, 2008.

FEATHERSTONE, M. Cultura de consumo e pós-modernismo. Trad. Júlio Assis Simões. São Paulo: Studio Nobel, 1995.

FISCHER, L. A. "Conversa urgente sobre uma velharia. Uns palpites sobre a vigência do regionalismo." Revista Cultura e Pensamento, No. 3, Dezembro/2007, p.127-141. Disponível em: http://www.cultura.gov.br/upload/cp_revista_ed3_web_1203381565.pdf

SANT'ANNA, A. R. de. “Que fazer de Marcel Duchamp?” O Estado de S. Paulo, 01/ago/2008, Caderno 2, p. D-6.

TRAQUINA, N. Teorias do Jornalismo Vol. II: A tribo jornalística - uma comunidade interpretativa transnacional. Florianópolis: Insular, 2005.

\section{Notas:}

(1) Em sua primeira versão, este trabalho foi apresentado ao Grupo de Trabalho Cultura das Mídias, no XVIII Encontro da Compós (PUC-MG, Belo Horizonte/MG, junho de 2009).

(2) Conforme Ericson, Baranek e Chan, são seis os valores-notícia de construção: simplificação, amplificação, relevância, personalização, dramatização e consonância (Cf. TRAQUINA, 2005: 91-93).

(3) As críticas escolhidas são: "Que fazer de Marcel Duchamp?", de Affonso Romano de Sant'anna; "Esta Bienal reflete a arte contemporânea?", de Aracy Amaral e "Conversa urgente sobre uma velharia. Uns palpites sobre a vigência do regionalismo", de Luís Augusto Fischer.

\section{Mini Currículo :}

Professor do Programa de Pós-Graduação em Comunicação Midiática da Universidade Estadual Paulista (Unesp). 